\title{
Case series: Ultrasonography may assist epidural insertion in scoliosis patients
}

\author{
[Séries de cas : l'échographie peut faciliter l'insertion péridurale chez des patients \\ atteints de scoliose]
}

Andrew McLeod FrCA, ${ }^{*}$ Antony Roche FrCA $\uparrow$ Mary Fennelly FrCA*

Purpose: Epidural cannulation is a difficult technique in the patient undergoing scoliosis repair, due to axial rotation of the vertebral bodies, as well as angulation of the spinal processes. This case series was performed to investigate whether ultrasonography could facilitate epidural insertion in patients with scoliosis, by assessing the degree of vertebral body rotation.

Clinical features: Eleven patients scheduled for corrective scoliosis surgery were studied. The spine was examined ultrasonically using a portable ultrasound system with a $38-\mathrm{mm}$ linear probe in two-dimensional B mode. The angulation of the probe head (measured using an inclinometer held in alignment with its long axis) at which the echo signals from the laminae became level on the screen was taken to correspond to the degree of vertebral rotation. The least rotated (most neutral) vertebral interspace was located, and a supervised anesthesiology trainee then performed epidural catheter insertion, using a loss-of-resistance technique. Bupivacaine $0.125 \%$ with fentanyl $4 \mu \mathrm{g} \cdot \mathrm{mL}^{-1}$ was infused after surgery, and successful epidural placement was indicated by the presence of effective analgesia and loss of sensation to cold stimuli. In ten patients, the neutral space could be identified, while in one, the least rotated space was measured at $15^{\circ}$ from the horizontal. Epidural catheterization was successful in eight of I I patients at the identified level. In two other patients, the space above was employed. The information was described as helpful in seven patients.

Conclusion: We conclude that ultrasonography may have a potential role to facilitate insertion of epidural catheters in patients with scoliosis.
Objectif : La mise en place d'un cathéter péridural est difficile chez le patient qui doit subir la correction chirurgicale d'une scoliose, à cause de la rotation axiale des corps vertébraux et de l'angulation des apophyses rachidiennes. Nous voulions vérifier si l'échographie pouvait faciliter l'insertion péridurale dans les cas de scoliose, en évaluant le degré de rotation du corps vertébral.

Éléments cliniques : Onze patients admis pour la correction chirurgicale d'une scoliose ont participé à l'étude. Un examen échographique de la colonne a été fait en mode $B$ bidimensionnel avec un système portable comportant une sonde linéaire de $38 \mathrm{~mm}$. L'angulation de l'extrémité de la sonde (mesurée avec un inclinomètre aligné avec son axe long), à laquelle les échos provenant de la lame se maintenaient horizontaux à l'écran, est présumée correspondre au degré de rotation vertébrale. L'espace intervertébral le moins dévié (le plus neutre) a été localisé et, sous supervision, un résident en anesthésiologie a inséré un cathéter péridural selon la technique de perte de résistance. De la bupivacaïne à $0,125 \%$ et $4 \mu \mathrm{g} \cdot \mathrm{mL}^{-1}$ de fentanyl ont été perfusés après l'opération. L'efficacité de l'analgésie et la perte de sensation au froid indiquaient la bonne position du cathéter. Chez dix patients, l'espace neutre a été repéré, mais chez un patient, l'espace le moins dévié était à $15^{\circ}$ de l'horizontal. Le cathétérisme péridural a été réussi chez 8 des I I patients au niveau identifié. Chez deux autres patients, l'espace audessus a été utilisé. L'échographie a été jugée utile chez sept patients.

Conclusion : L'échographie peut faciliter l'insertion d'un cathéter péridural chez des patients atteints de scoliose.

From the Department of Anaesthesia, ${ }^{*}$ Royal National Orthopaedic Hospital, Stanmore, United Kingdom; and the Department of Anesthesiology, $†$ Duke University Medical Center, Durham, North Carolina, USA.

Address correspondence to: Dr. Andrew McLeod, Department of Anaesthetics, Queen Alexandra Hospital, Cosham, Portsmouth, PO6 3LY, United Kingdom. Phone: +44 2392 286279; Fax: +44 2392 286681; E-mail: andrew.mcleod@porthosp.nhs.uk Sources of support: This study was carried out with the loan of a portable ultrasound machine made by Sonosite Ltd, Hitchin, UK. There was no other form of support, and there are no conflicts of interest to disclose.

Accepted for publication January 17, 2005.

Revision accepted March 29, 2005.

CAN J ANESTH 2005/52: $7 /$ pp 717-720 
$\mathrm{P}$

ATIENTS with scoliosis may benefit from postoperative epidural analgesia following spinal surgery, due to potentially superior analgesia, and improved respiratory function. Direct placement of an epidural catheter can be performed during posterior surgical approaches, but for anterior surgical approaches, the familiar loss-ofresistance technique is employed. In the scoliotic spine, vertebral bodies are rotated axially, with their spinous processes facing into the concavity of the curve. The degree of rotation (which determines the orientation needed for midline needle insertion) is difficult to estimate clinically or from simple inspection of $x$-rays, and there is currently no technique suitable for immediate operating room use. Ultrasound can help to estimate the depth and location of the epidural space. ${ }^{1-3}$ One study has previously measured vertebral rotation in scoliotic patients using ultrasound imaging, and reported values that correlated well with radiologically derived calculations. ${ }^{4}$ This case series aimed to investigate whether this same technique could be used before epidural catheter insertion, and contribute to successful placement.

\section{Methods}

This study had received Institutional Ethics Committee approval, and written informed consent was obtained from all patients (or their parents) before recruitment. Any patient with scoliosis, for whom placement of an epidural catheter was planned prior to corrective surgery, was invited to participate. Patient age, gender, height, weight and diagnosis were recorded, together with the Cobb angle, which quantifies the severity of spinal curvature, as measured from preoperative radiographs. ${ }^{5}$

Assessment of the spine, and insertion of the epidural catheter was performed after induction of anesthesia, which followed our institution's routine practice in pediatric and young-adult patients with scoliosis. Each patient was placed in the lateral position, and the same investigator examined the spine ultrasonically. A portable ultrasound system (Sonosite $180 \AA$, Sonosite Ltd, Hitchin, UK) with a $38-\mathrm{mm}$ linear probe was used, which could insonate to a depth of $70 \mathrm{~mm}$. The spine was examined in two-dimensional $\mathrm{B}$ mode at each level to assess the degree of rotation, using the method described by Suzuki and colleagues. ${ }^{4}$ The probe head was placed in the space between two spinous processes, perpendicular to the long axis of the spine. Rotation (relative to the horizontal plane) was measured in degrees using an inclinometer held in careful alignment with the long axis of the probe, as shown in Figure 1. The laminae

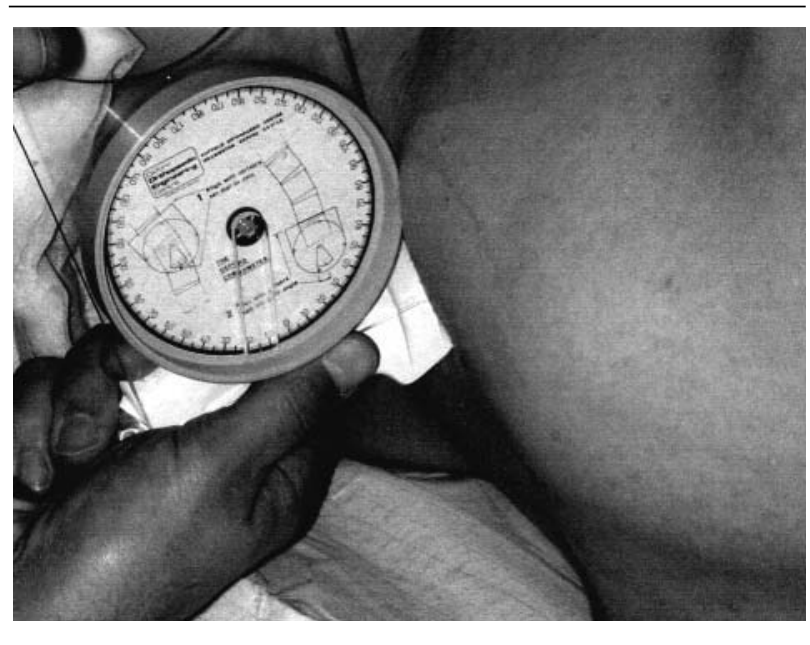

FIGURE 1 Ultrasound probe placed between two spinous processes, perpendicular to the long axis of the spine. The inclinometer is held in alignment with the long axis of the probe head.

appear as bright echogenic bands at 2 to $4 \mathrm{~cm}$ depth either side of the midline, as shown in Figure 2. When they appear level in the ultrasound image, the angulation of the probe head corresponds to the degree of rotation of the vertebral bodies. The level of the most neutral space was estimated by counting the spinous processes, and recorded. An experienced anesthesia trainee then attempted to insert an epidural catheter at this level, following instructions to direct the needle in the horizontal plane. A midline approach was employed, using a 16-gauge Tuohy needle (SIMS Portex, Hythe, Kent, UK) and loss-of-resistance technique. An epidural catheter was inserted, but local anesthetic was not instilled until perioperative spinal cord monitoring had been discontinued. An initial bolus dose of 5 to $10 \mathrm{~mL} 0.25 \%$ bupivacaine, followed by an infusion of $0.125 \%$ bupivacaine with fentanyl 4 $\mu \mathrm{g} \cdot \mathrm{mL}^{-1}$ was administered. Confirmation of correct placement was based upon effective analgesia, and the presence of bilateral loss of sensation to cold, assessed in the postoperative care unit. Pain was scored on a simple numerical analogue scale 0 to 4 where 0 represents no pain, and 4, extreme pain. The anesthesiologist performing epidural insertion was asked whether the ultrasound information had been helpful, i.e., they had been able to successfully insert an epidural catheter with the needle in a horizontal orientation. Descriptive statistics were calculated using Microsoft Excel® software. 


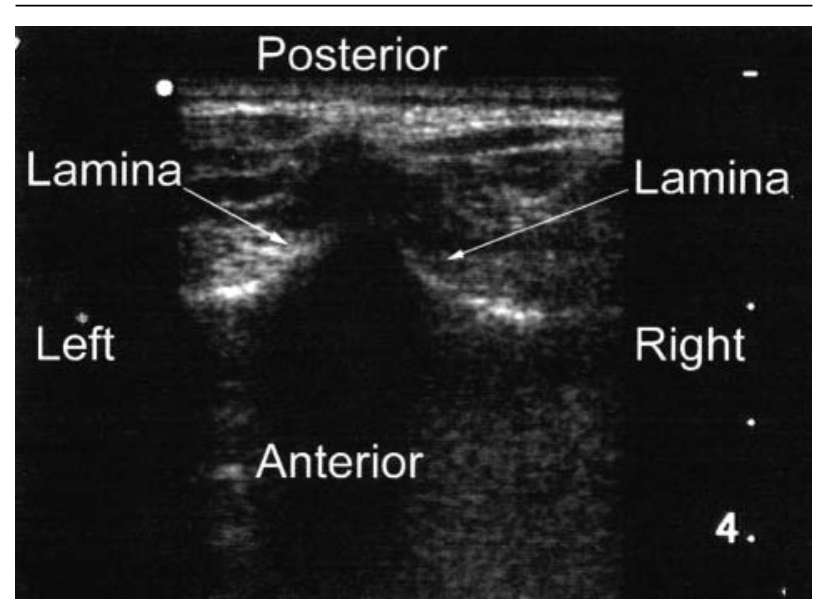

FIGURE 2 Transverse ultrasound image of the spine. The laminae are seen as bright echogenic curving bands either side of the mid-line. The laminae appear level when the probe head is directed in the same orientation as the vertebra. Marks to the right indicate depth in $\mathrm{cm}$.

\section{Results}

The Table summarizes demographic and clinical characteristics of the patient group. In two patients, arm span was used as a surrogate measure for height. Each study was completed in ten to $15 \mathrm{~min}$, and image quality was sufficient to visualize the laminae in all cases. A non-rotated spinal interspace was identified in ten patients, at a spinal level ranging from $\mathrm{T} 6 / 7$ to $\mathrm{T} 12 / \mathrm{Ll}$. In one patient, the least rotated interspace was measured at the $\mathrm{L} 2 / 3$ level, and was found to be $15^{\circ}$ upwards from the horizontal plane (and epidural insertion was successful using a slight upwards angulation of approach). Overall, epidural catheterization was successful at the identified level in eight patients, and in two, the space above was used as a second resort. In one patient, a senior anesthesiologist was required to complete the procedure. All patients had good analgesia postoperatively (pain score 1 out of 4 or below), and bilateral loss of hot/cold sensation. The trainee reported the information provided by ultrasound to have been of help in seven of the 11 cases. In the four cases where it had not, they had been unable to insert an epidural directed in the horizontal orientation, and had had to resort to an alternative angulation, or spinal interspace.

\section{Discussion}

We have demonstrated in this clinical series that ultrasound can be used in the operating room by anesthesia personnel to assess the degree of axial rotation of
TABLE Patient demographic and clinical data - mean (standard deviation)

\begin{tabular}{ll}
\hline Number & 11 \\
Female & 8 \\
Male & 3 \\
Adolescent idiopathic scoliosis & 10 patients \\
Scoliosis associated with telangectasia & 1 patient \\
Age (median and range) & $15 \mathrm{yr}(13-23)$ \\
Weight & $50.5 \mathrm{~kg}(11.5)$ \\
Height & $1.63 \mathrm{~m}(0.11)$ \\
Body mass index & $18.8 \mathrm{~kg} \cdot \mathrm{m}^{-2}(2.28)$ \\
Cobb angle & $60^{\circ}\left(17^{\circ}\right)$ \\
\hline
\end{tabular}

vertebral bodies in scoliosis patients, and to locate the least rotated space. We have also obtained some evidence that this information can be of value during epidural catheterization for anesthesiologists unfamiliar with scoliosis. A limitation of this report is that we have not attempted to make a controlled comparison to establish whether this technique improves the success, or speed of epidural insertion. Clearly, a randomized controlled trial would be warranted to resolve this issue.

In our study, we did not attempt to corroborate the ultrasound assessments with radiological measurements, or perform computed tomography scans of the patients. The recorded measurements did not take into account vertebral deformation, where vertebrae are distorted, as well as rotated. Also, we measured rotation relative to the horizontal plane, although this approach may not have corresponded exactly to the patients' own midline saggital plane, despite careful positioning. However, anesthesiologists are familiar with directing a needle in the horizontal plane, and it is our view that this space could be the most useful one to identify. The participating trainees all had more than four years experience in anesthesiology, and were proficient in the technique of inserting epidural catheters into patients with normal spines. We therefore believed that they could potentially obtain most benefit from information derived from this technique.

A number of factors influence the difficulty of inserting epidural catheters, such as estimating the depth of the epidural space, and the longitudinal angulation of the spinous processes. In the scoliotic spine, the rotation of the vertebral bodies adds a further unknown variable. The spinous processes face into the concavity of the curve, which may also be counter-intuitive to those unfamiliar with scoliosis. At our institution, all trainees are instructed in the anatomical distortions of the scoliotic spine. The 
Cobb angle is routinely measured from preoperative radiographs, but its relationship with vertebral rotation is complex. Moe and Nash have described a technique that estimates rotation from radiographs, ${ }^{6}$ but this method requires some familiarity with spinal radiographs, and the information derived may not easily translate to the clinical situation. In this study, the participating anesthesiology trainees were not explicitly made aware of radiological information, but relied on the information we had obtained from ultrasound.

The technique described by Suzuki et al., ${ }^{4}$ was intended for the assessment of scoliosis only, rather than for guiding interventions, and its potential application in anesthesia has not been described previously. Ultrasound has been successfully used to estimate the depth of the epidural space in obstetric patients, ${ }^{1}$ and to improve the accuracy with which anesthesiologists identify the lumbar interspace level. ${ }^{2,3}$ In obstetrical practice, Grau $e t a l$. reported that ultrasound assistance reduced the number of epidural insertion attempts. ${ }^{7}$ The same group reported improved learning curves for trainees performing their first 60 epidural cannulations using ultrasound guidance compared to those not using the technique. ${ }^{8}$ Ultrasound has wider applications, including central venous cannulation and peripheral nerve blockade, which are gaining in acceptance. ${ }^{9}$ Indeed, ultrasonography is now being seen as an essential tool in any practice performing central venous access, as the British National Institute for Clinical Excellence (NICE) recommended in the 2002 NICE clinical guidelines for the use of ultrasound in central venous cannulation. ${ }^{10}$ Many authors have also recently described the success of ultrasound-guided brachial plexus blockade aiding visualization of needle placement and local anesthetic spread in a real-time manner. ${ }^{11,12}$ In the future, use of ultrasound for invasive procedures may increasingly be seen as best practice, particularly in training contexts. ${ }^{9,13}$

Although a number of papers describe the success of ultrasound in facilitating lumbar and caudal epidural cannulation,,$^{7,8,14}$ this is the first case series describing its use in epidural cannulation of the more difficult thoracic region, in patients with significant axial rotation of their vertebrae due to severe scoliosis requiring surgical correction. A large randomized controlled trial is warranted to assess if this novel technique increases the success rate of epidural catheter placement, as well as improving postoperative analgesia.

\section{Acknowledgement}

We gratefully acknowledge the support of Sonosite Ltd Hitchin, UK, for the loan of a portable ultrasound system.

\section{References}

1 Currie JM. Measurement of the depth to the extradural space using ultrasound. Br J Anaesth 1984; 56: 345-7.

2 Furness G, Reilly MP, Kuchi S. An evaluation of ultrasound imaging for identification of lumbar intervertebral level. Anaesthesia 2002; 57: 277-80.

3 Watson MJ, Evans S, Thorp JM. Could ultrasonography be used by an anaesthetist to identify a specified lumbar interspace before spinal anaesthesia? Br J Anaesth 2001; 90: 509-11.

4 Suzuki S, Yamamuro T, Shikata J, Shimizu K, Iida $H$. Ultrasound measurement of vertebral rotation in idiopathic scoliosis. J Bone Joint Surg 1989; 71-B: 252-5.

$5 \mathrm{Cobb} J R$. Outline for the study of scoliosis. In: Blount WP, Banks SW (Eds). The American Academy of Orthopaedic Surgeons, Instructional Course Lectures, vol 5. Ann Arbor, MI: JW Edwards; 1948: 261-75.

6 Nash CL Jr, Moe JH. A study of vertebral rotation. J Bone Joint Surg (Am) 1969; 51-A: 223-9.

7 Gran T, Leipold RW, Conradi R, Martin E, Motsch J. Ultrasound imaging facilitates localization of the epidural space during combined spinal and epidural anesthesia. Reg Anesth Pain Med 2001; 26: 64-7.

8 Grau T, Bartusseck E, Conradi R, Martin E, Motsch J. Ultrasound imaging improves learning curves in obstetric epidural anesthesia: a preliminary study. Can J Anesth 2003; 50: 1047-50.

9 Hatfield A, Bodenham A. Ultrasound: an emerging role in anaesthesia and intensive care. $\mathrm{Br} \mathrm{J}$ Anaesth 1999; 83: 789-800.

10 National Institute for Clinical Excellence. Final Appraisal Determination. Ultrasound locating devices for placing central venous catheters. Available from URL; http://www.nice.org.uk/page.aspx?o=35419.

11 Sandhu NS, Capan LM. Ultrasound-guided infraclavicular brachial plexus block. Br J Anaesth 2002; 89: 254-9.

12 Chan VW, Perlas A, Rawson R, Odukoya O. Ultrasound-guided supraclavicular brachial plexus block. Anesth Analg 2003; 97: 1514-7.

13 Scott $D H$. 'In the country of the blind, the one-eyed man is king', Erasmus (1466-1536) (Editorial). Br J Anaesth 1999; 82: 820-1.

14 Chen CP, Tang SF, Hsu TC, et al. Ultrasound guidance in caudal epidural needle placement. Anesthesiology 2004; 101: 181-4. 